\title{
The Ventilatory Strategy to Minimize Expiratory Flow Rate in Ventilated Patients with Chronic Obstructive Pulmonary Disease
}

This article was published in the following Dove Press journal: International Journal of Chronic Obstructive Pulmonary Disease

\author{
Norihiko Tsuboi (D) \\ Kaoru Tsuboi' \\ Nobuyuki Nosaka ${ }^{1,2}$ \\ Nao Nishimura' \\ Satoshi Nakagawa' \\ 'Critical Care Medicine, National Center \\ for Child Health and Development, \\ Tokyo, Japan; ${ }^{2}$ Department of Intensive \\ Care Medicine, Tokyo Medical and Dental \\ University, Tokyo, Japan
}

\begin{abstract}
Although the pathophysiology of chronic obstructive pulmonary disease (COPD) is multifactorial, central airway collapse is reported to have a great impact on symptom severity. In COPD patients, positive pressure formed by hyperinflated lungs compressing the tracheal wall and negative changes in intratracheal static pressure due to rapid expiratory flow velocity at the beginning of expiration collapse the trachea. This phenomenon can be explained by fluid dynamics theory. Our hypothesis is that ventilatory strategy focusing on minimization of expiratory flow rate may be advantageous for patients receiving mechanical ventilation for COPD. If appropriate counter pressure could be applied on exhalation, patients may be able to exhale slowly with reduced expiratory flow rates which may prevent negative changes of the intratracheal static pressure. We devised a new conceptual ventilation mode "minimized expiratory flow rate ventilation $(\mathrm{MExV})$ " which applies regulated counter pressure on exhalation. The conceptual waveforms of "minimized expiratory flow rate ventilation" including flow rate, volume, and airway pressure are shown, compared with typical waveforms of the conventional ventilation modes.
\end{abstract}

Keywords: COPD, tracheomalacia, fluid dynamics, minimized expiratory flow rate ventilation, flow-controlled ventilation

\section{Introduction}

Chronic obstructive pulmonary disease (COPD) is a type of obstructive lung disease that poses a major health and economic burden worldwide. ${ }^{1}$ Acute exacerbation of COPD forms a major component of COPD-related mortality. ${ }^{2}$ After the onset of acute exacerbation, patients present with signs of increased work of breathing and reduced forced expiratory volume in 1 second (FEV1). ${ }^{3}$

Although the pathophysiology of COPD is multifactorial, central airway collapse may have a great impact on symptom severity. ${ }^{4}$ Once the trachea collapses immediately after the beginning of exhalation, expiratory flow is severely limited, resulting in a decrease in FEV1. Nearly half of the patients with COPD were reported to have their tracheas collapsed during exhalation. This finding was confirmed by dynamic airway CT imaging and bronchoscopy. ${ }^{4,5}$ While coexistence of tracheomalacia has been explained to be responsible for this change, fluid dynamics theory revealed that positive pressure formed by hyperinflated lungs compressing the tracheal wall and negative changes in intratracheal static pressure
Correspondence: Norihiko Tsuboi Critical Care Medicine, National Center for Child Health and Development, 2-10I Okura, Setagaya-ku, Tokyo, I57-8535, Japan

Tel $+8|-334| 60 \mid 8 I$

Fax +8I-224I62222

Email tsuboi-n@ncchd.go.jp
International Journal of Chronic Obstructive Pulmonary Disease 2021:16 301-304

301 
due to rapid expiratory flow velocity on expiration leads to tracheal collapse in COPD patients. ${ }^{6,7}$

A new conceptual ventilator setting, "minimizing expiratory flow rate ventilation (MExV)" may avoid tracheal collapse and may be useful in both non-invasively and invasively ventilated patients with COPD.

\section{Hypothesis}

The ventilatory strategy of minimizing expiratory flow rate may be advantageous for ventilated patients with COPD.

\section{A Volume Control Ventilation}

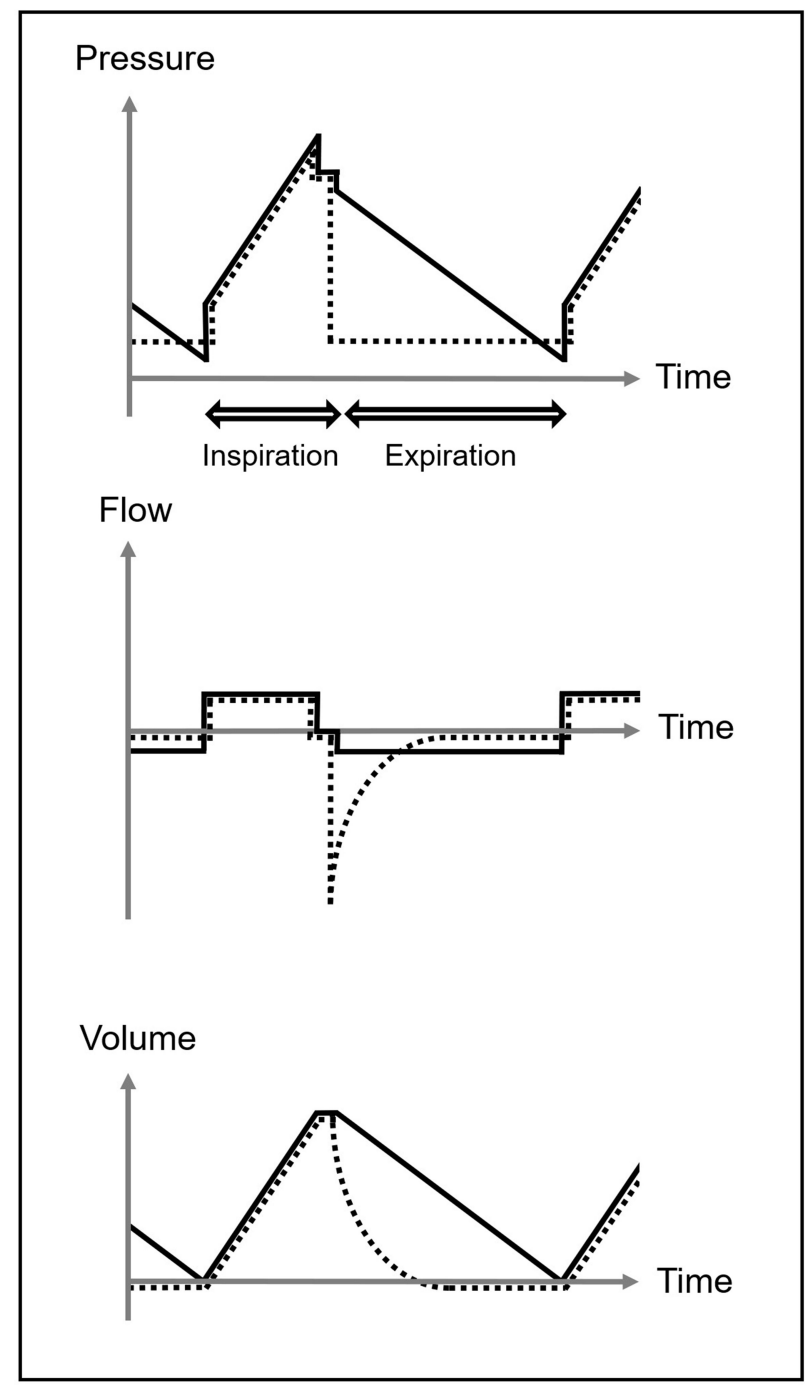

Minimized expiratory flow rate ventilation Current volume control ventilation

\section{Fluid Dynamics Equations}

When removing the effect of gravity, the Bernoulli equation for steady frictionless incompressible flow implies the following:

$$
p+\frac{1}{2} \rho u^{2}=\text { const }
$$

where:

$p$ is the static pressure at the chosen point $[\mathrm{Pa}]$ $\left(=\left[\mathrm{N} / \mathrm{m}^{2}\right]=\left[\mathrm{kg} / \mathrm{m} \cdot \mathrm{s}^{2}\right]\right)$,

\section{B Pressure Control Ventilation}
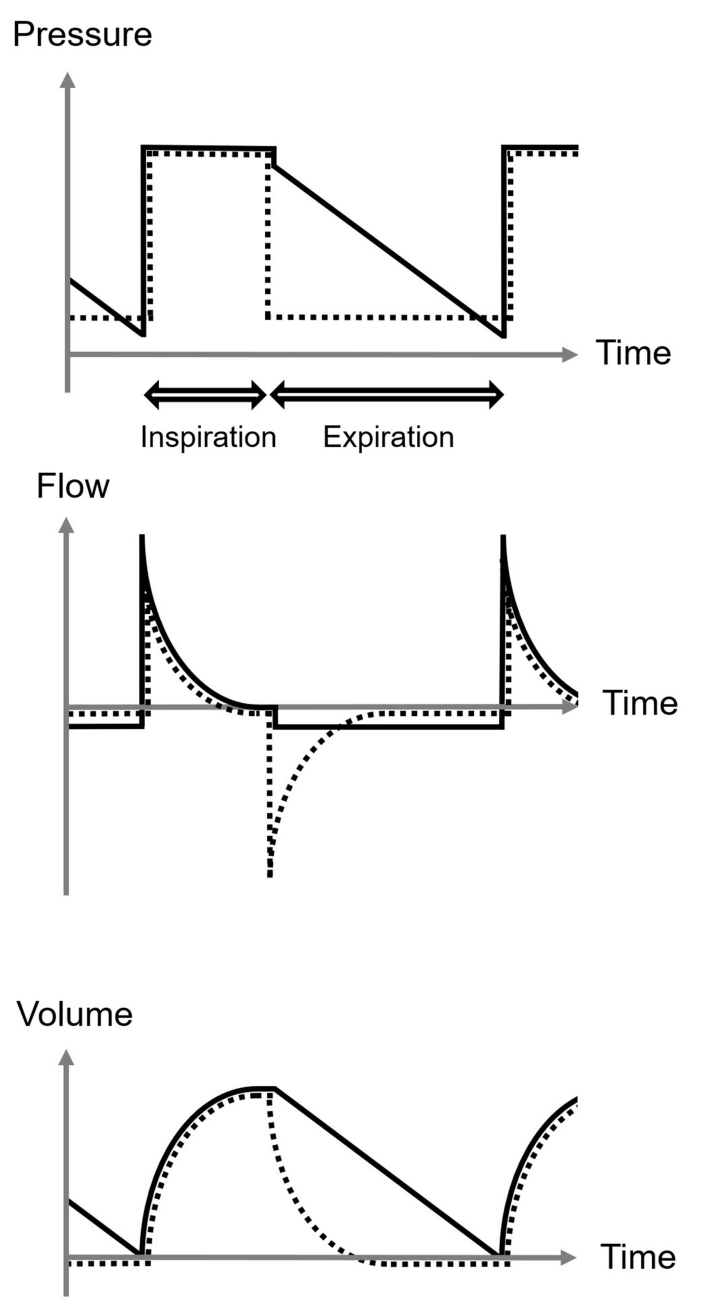

Minimized expiratory flow rate ventilation Current pressure control ventilation

Figure I Minimized expiratory flow rate ventilation. The curves of pressure, flow, and volume during a respiratory cycle in the conceptual ventilation mode "minimized expiratory flow rate ventilation" are shown compared with those of current volume control ventilation (A) and pressure control ventilation (B). 
$\rho$ is the density of the fluid at all points in the fluid $[\mathrm{kg} /$ $\left.\mathrm{m}^{3}\right]$, and

$u$ is the fluid flow velocity at a point on a streamline $[\mathrm{m} / \mathrm{s}]$.

" $\frac{1}{2} \rho u^{2}$ " is known as "dynamic pressure".

From Equation (1), it can be said that the rapid expiratory flow through the trachea increases local dynamic pressure and results in decreased local static pressure.

\section{Conceptual Ventilation Mode}

In mechanically ventilated patients, inspiration is forced by externally applied positive pressure. In contrast, exhalation is passive and depends on the time constant of the total respiratory system in most of the commercially available ventilation modes. A large pressure gradient is created upon opening of exhalation valve, and expiratory flow rate rapidly increases to a peak. If appropriate counter pressure could be applied on exhalation, patients may be able to exhale slowly with reduced expiratory flow rates which may prevent negative changes of the intratracheal static pressure. Thus, counter pressure on exhalation may prevent central airway collapse and lung hyperinflation. This mechanism is similar to "pursed lip breathing" often seen in these patients. ${ }^{8,9}$

From these hypotheses, we devised a new conceptual ventilation mode "minimized expiratory flow rate ventilation (MExV)" which applies regulated counter pressure on exhalation. This mode could be added as an optional setting to the expiratory phase of conventional pressure- or volume-control ventilation. Figure 1 shows the conceptual waveforms of $\mathrm{MExV}$ including flow rate, volume, and airway pressure, compared with typical waveforms of conventional ventilation modes.

The latest ventilators released (Evone, Ventinova Medical B.V., Eindhoven, the Netherlands) have a ventilation mode called "flow-controlled ventilation (FCV)". FCV is a mode based on controlled inspiratory and expiratory flow. The inspiratory flow is continuously controlled by advanced mass flow regulators; the expiratory flow is controlled by regulated suctioning. ${ }^{10,11}$ This mode allows the patient to exhale slowly by maintaining the expiratory flow rate at a constant rate, and thus, patients with obstructive lung disease may be an ideal target. However, FCV cannot be successfully achieved when there is a leakage in the respiratory circuit, making this mode available only in invasive ventilation with a cuffed endotracheal tube. MExV limits the expiratory flow rate by adding counter pressure on expiration enabling this mode to be available in both invasive and non-invasive ventilation. As patients with COPD are most often elderly and frail, non-invasive ventilation is the gold standard of respiratory management. Thus, MExV could be a promising strategy for these patients.

\section{Limitation}

First, we have no actual patient data for this article. Second, airway obstruction in COPD patients is caused not only by central airway collapse, but also by small airway remodeling, sputum bolt, and inflammatory infiltration. It is well accepted that rapid expiratory flow helps loosen and protrude sputum bolts. Therefore, the strategy to reduce expiratory flow rate may impair airway hygiene in these patients. However, central airway collapse due to rapid air flow velocity significantly limits expiratory flow, paradoxically leading to impaired airway clearance. Patients with severe COPD have decreased forced vital capacity compared with slow vital capacity. ${ }^{12}$ This may reflect central airway collapses in these patients.

\section{Abbreviations}

COPD, chronic obstructive pulmonary disease; FEV1, forced expiratory volume in 1 second; $\mathrm{MExV}$, minimizing expiratory flow rate ventilation; FCV, flow-controlled ventilation.

\section{Disclosure}

The authors report no conflicts of interest in this work.

\section{References}

1. Rabe KF, Hurd S, Anzueto A, et al. Global strategy for the diagnosis, management, and prevention of chronic obstructive pulmonary disease: GOLD executive summary. Am J Respir Crit Care Med. 2007;176:532-555. doi:10.1164/rccm.200703-456SO

2. Hillas G, Perlikos F, Tzanakis N. Acute exacerbation of COPD: is it the "stroke of the lungs"? Int J Chron Obstruct Pulmon Dis. 2016;11:1579-1586. doi:10.2147/COPD.S106160

3. Watz H, Tetzlaff K, Magnussen H, et al. Spirometric changes during exacerbations of COPD: a post hoc analysis of the WISDOM trial. Respir Res. 2018;19:251. doi:10.1186/s12931-018-0944-3

4. Ernst A, Odell DD, Michaud G, et al. Central airway stabilization for tracheobronchomalacia improves quality of life in patients with COPD. Chest. 2011;140:1162-1168. doi:10.1378/chest.10-3051

5. Sverzellati N, Rastelli A, Chetta A, et al. Airway malacia in chronic obstructive pulmonary disease: prevalence, morphology and relationship with emphysema, bronchiectasis and bronchial wall thickening. Eur Radiol. 2009;19:1669-1678. doi:10.1007/s00330-009-1306-9

6. Kitaoka H. Reconstruction of respiratory physiology based on flow dynamics. J Fluid Sci Technol. 2018;13:JFST0023. doi:10.1299/ jfst.2018jfst0023

7. Tsuboi N, Matsumoto S, Nishimura N, et al. Fluid dynamics approach to airway obstruction. Med Hypotheses. 2019;132:109341. doi:10.1016/j. mehy.2019.109341 
8. Visser FJ, Ramlal S, Dekhuijzen PN, et al. Pursed-lips breathing improves inspiratory capacity in chronic obstructive pulmonary disease. Respiration. 2011;81:372-378. doi:10.1159/000319036

9. Bianchi R, Gigliotti F, Romagnoli I, et al. Patterns of chest wall kinematics during volitional pursed-lip breathing in COPD at rest. Respir Med. 2007;101:1412-1418. doi:10.1016/j.rmed.2007.01.021

10. Weber J, Straka L, Borgmann S, et al. Flow-controlled ventilation (FCV) improves regional ventilation in obese patients - a randomized controlled crossover trial. BMC Anesthesiol. 2020;20:24. doi:10.1186/ s12871-020-0944-y
11. Weber J, Schmidt J, Straka L, et al. Flow-controlled ventilation improves gas exchange in lung-healthy patients- a randomized interventional cross-over study. Acta Anaesthesiol Scand. 2020;64:481-488. doi:10.1111/aas.13526

12. Yuan W, He X, Xu QF, et al. Increased difference between slow and forced vital capacity is associated with reduced exercise tolerance in COPD patients. BMC Pulm Med. 2014;14:16. doi:10.1186/14712466-14-16

\section{Publish your work in this journal}

The International Journal of COPD is an international, peer-reviewed journal of therapeutics and pharmacology focusing on concise rapid reporting of clinical studies and reviews in COPD. Special focus is given to the pathophysiological processes underlying the disease, intervention programs, patient focused education, and self management protocols. This journal is indexed on PubMed Central, MedLine and CAS. The manuscript management system is completely online and includes a very quick and fair peer-review system, which is all easy to use. Visit http://www.dovepress.com/testimonials.php to read real quotes from published authors. 